\title{
The Role of Logic in Teaching Proof
}

\author{
Susanna S. Epp
}

1. INTRODUCTION. Over the past several decades, many of those involved with mathematics education at the college and university level have turned their attention to the difficulties students experience in mathematics courses requiring them to write proofs. Because even mathematics majors have trouble in more advanced courses, a number of mathematicians have written "transition" books whose aim is to bridge the gap between lower-level, computationally oriented courses and upper-level classes where deductive reasoning and abstraction play a major role. See, for example, books by Smith, Eggen, and St. Andre [44], Mason [28], Lucas [27], Velleman [50], Solow [45], and Fletcher and Patty [18]. Moreover, because computer science students also need to learn to operate in a mathematically sophisticated environment, one of the goals of discrete mathematics courses is to enhance students' logical reasoning and proof-writing abilities. See, for example, Gersting [20], Johnsonbaugh [26], Rosen [38], Ross and Wright [39], Gries and Schneider [22], Epp [13], and Dubinsky and Fenton [9]. Over the same period, researchers in mathematics education have been investigating the cognitive processes that underlie students' difficulties with proof production. A summary of some of this research can be found in Tall [46]. Among recent contributors are Goetting [21], Harel and Sowder [23], Moore [30], [31], Selden and Selden [41], [42], and Thompson [49]. Many additional references and articles can be found on the Internet website "Preuve," the "International Newsletter for the Teaching and Learning of Proof" (http://www-didactique.imag.fr/preuve/).

In the late 1970s, before texts for transition courses had become generally available, I started teaching a course to provide background for students who would go on to take advanced undergraduate courses in mathematics and computer science. Initially, I had assumed that the reason our students were doing so poorly in our advanced courses was that the teachers moved too quickly to "interesting mathematics" and paid inadequate attention to basic material such as sets, functions, and relations. I expected that the new course would solve this problem by giving students an adequate amount of time to focus exclusively on foundations.

As I taught the course, however, I found that my students' difficulties were much more profound than I had imagined. Indeed, I was almost overwhelmed by the poor quality of their proof-writing attempts. Often their efforts consisted of little more than a few disconnected calculations and imprecisely or incorrectly used words and phrases that did not even advance the substance of their cases. My students seemed to live in a different logical and linguistic world from the one I inhabited, a world that made it very difficult for them to engage in the kind of abstract mathematical thinking I was trying to help them learn.

2. THE NEED FOR INSTRUCTION IN FORMAL REASONING SKILLS. Evaluating the truth and falsity of even very simple mathematical statements involves complex cognitive activity. The examples to follow analyze the reasoning that underlies valid determinations of the truths of three mathematical statements. A person need not have conscious knowledge of the logical principles used in the arguments, but 
the principles must be employed in order for the reasoning to be valid. For instance, consider how a person might validly determine that

\section{the square of any rational number is rational.}

1. One must realize that the statement makes a claim about every element in the infinite set of rational numbers, that no amount of checking the claim for a finite number of instances will suffice to establish its general truth.

2. One must have a sense that, to establish the general truth of the claim, one supposes one is given a particular rational number about which one knows nothing besides the fact that it is rational. One then must show that the square of this number is rational.

3. One must be aware (perhaps unconsciously) of the importance of definitions in evaluating mathematical claims, that to draw a conclusion about a rational number one must have a precise understanding of what "rational number" means.

4. One must appreciate (perhaps unconsciously) that definitions are universal statements and that they have both an "if" and an "only if" direction. Given a particular but arbitrarily chosen rational number $r$, one instantiates the "only if" direction of the definition to conclude that $r$ can be written in a certain way. Later, after one has established that $r^{2}$ has a certain form, one instantiates the "if" direction of the definition to conclude that $r^{2}$ is rational.

5. One needs to have a sense that the rule for multiplying fractions is a universal statement that applies to all pairs of fractions, even to two that are the same.

As another example of the complex underpinning of a simple disproof, consider the reasoning needed to establish validly that the following statement is false:

$$
\text { for all real numbers } a \text { and } b \text {, if } a>b \text { then } a^{2}>b^{2} \text {. }
$$

1. One must realize (consciously or unconsciously) that the given statement is universal, that since it makes a claim about all pairs of real numbers, a single counterexample will serve to show that it is false. In other words, one must have some, perhaps unconscious, awareness that the negation of a universal statement is existential.

2. One must understand that to obtain a counterexample, one must find real numbers $a$ and $b$ so that $a>b$ but $a^{2} \ngtr b^{2}$. That is, one must be aware (consciously or unconsciously) that the negation of if $p$ then $q$ is $p$ and not $q$.

3. Having understood the requirements a counterexample must satisfy, one must realize that it may be necessary to explore a variety of types of real numbers to find one.

An example of the reasoning underlying a valid elementary argument by contradiction is illustrated in the proof that

$$
\text { for all real numbers } x \text {, if } x \text { is irrational then }-x \text { is irrational. }
$$

1. One must have a sense that one can evaluate the truth of the statement by supposing that there is a real number $x$ for which $x$ is irrational and $-x$ is rational and seeing whether this supposition leads logically to a contradiction.

2. Alternatively, one must either have a sense that the statement is logically equivalent to

for all real numbers $x$, if $-x$ is rational then $x$ is rational, 
or equivalently (and this involves the fact that $-(-x)=x$ and a rather sophisticated understanding of variables) that

for all real numbers $x$, if $x$ is rational then $-x$ is rational.

Also one must know how to establish the truth of this statement by a direct argument; in other words, one either needs an intuition for the structure of proof by contradiction or for the fact that a conditional statement and its contrapositive are logically equivalent.

Many mathematicians take the reasoning described in these examples for granted. Yet in many years of working with several thousand such students at a university classified as "selective," I have observed that very few have an intuitive understanding of the reasoning principles that I have listed. For detailed discussions about the types of difficulties such students exhibit, see Selden and Selden [41], [42], Moore [30], [31], Epp [12], and Harel and Sowder [23]. Work by Thompson [49] and Goetting [21, pp. 142-148] indicates that statements requiring proof by contradiction or proof by contraposition are particular sources of difficulty, even for students who have taken advanced mathematics courses. Fishbein and Kedem [17] and Vinner [51] suggest that even when students appear to understand a correct proof for a mathematical statement, they may not appreciate that it obviates the need for further verification.

Since the 1960s, researchers such as Wason, Johnson-Laird, Legrenzi and Legrenzi, Ceraso and Provitera, Rips and Marcus, Taplin and Staudenmayer, Nisbett, and Cheng, among others, have been conducting experiments that indicate the extent to which subjects (usually college students) tend spontaneously to employ the rules of formal reasoning when they make deductions. Much of this work is summarized in Anderson [1, pp. 296-327], Evans [16], and Rips [37, pp. 14-30]. For instance, in a path-breaking experiment, which has been widely replicated and is known as the "selection task," Wason [53] showed that while all but a tiny fraction of students reliably use modus ponens even in the most abstract settings, a much smaller proportion can be counted upon to make use of modus tollens, and significant numbers commit the fallacies of affirming the consequent and denying the antecedent. ${ }^{1}$ The summaries in Anderson also describe research showing the kinds of difficulties faced by subjects when reasoning with quantifiers.

\section{DIFFERENCES BETWEEN EVERYDAY AND MATHEMATICAL LAN-}

GUAGE. One reason students may have problems with formal mathematical reasoning is that certain forms of statements are open to different interpretations in informal and formal settings. In everyday speech potential ambiguity occurs frequently, with context and world knowledge normally determining which interpretation to accept from among an array of possibilities. By contrast, mathematical language is required to be unambiguous, with each grammatical construct having exactly one meaning. This meaning, however, is often selected arbitrarily, by common convention, from among its potential natural language interpretations.

Traditional mathematical instruction makes very few of these linguistic conventions explicit to students. An exception is the word "or." Mathematicians often teach students that while "or" is used both exclusively and inclusively in ordinary speech,

\footnotetext{
${ }^{1}$ modus ponens: from $p \rightarrow q$ and $p$ we can deduce $q$; modus tollens: from $p \rightarrow q$ and $\sim q$ we can deduce $\sim p$; fallacy of affirming the consequent: from $p \rightarrow q$ and $q$ we can deduce $p$; fallacy of denying the antecedent: from $p \rightarrow q$ and $\sim p$ we can deduce $\sim q$
} 
it is always used inclusively in mathematics. However, they typically fail to provide guidance about the equally important distinctions between ordinary and mathematical language that relate to if-then and quantified statements.

For example, consider the variety of if-then statements used in everyday life. A parent who wishes to communicate to a child, "You can go to the movie if, and only if, you finish your homework" seldom, if ever, uses this sentence. Normally such a parent either promises "If you finish your homework, then you can go to the movie" or threatens "You can go to the movie only if you finish your homework." But the parent offering the reward in the first statement intends the child to understand that if the homework is not finished the child will not be able to go to the movie (even though this threat is not technically a part of the statement), and the parent threatening the punishment in the second statement would certainly not withhold the reward if the homework were completed (even though the statement made does not actually promise it). Similarly, most people reading a job advertisement saying, "Applications will be considered only if they are received by the deadline," would assume that if an application is submitted by the deadline it will be considered.

These examples illustrate how in everyday language both if-then and only-if statements are often meant to be interpreted as if-and-only-if statements. The informal convention appears to be that when one direction of an if-and-only-if statement is considered to be "obvious," only the less obvious direction is stated explicitly. Perhaps one reason why so many of my students make the "converse error" (from if $p$ then $q$ and $q$, deducing $p$ ) is that they have come to take for granted that the truth of if $p$ then $q$ implies the truth of if $q$ then $p$-unless their "world knowledge" obviously contradicts this assumption, which is not usually the case when they try to analyze a new mathematical situation.

My students also have difficulty accepting that $p$ only if $q$ is logically equivalent to if $p$ then $q$. A reason may be that in certain real-world situations the statements are not interchangeable. If we try to apply the equivalence to if-then statements that express causal or temporal relationships, the result is nonsense. For instance, "If it rains, then I won't go," would be equivalent to "It rains only if I won't go," which is gibberish.

Many of my students also make mistakes when they try to negate if-then statements. In mathematical logic the negation of if $p$ then $q$ is simply $p$ and not $q$, and this has important and broad ramifications for how mathematical arguments are structured. Ordinary language contains many different varieties of if-then statements besides the mathematical kind - ones referring to causal relationships, temporal relationships, counterfactual situations, and so forth. There are conventions for negating if-then in these other situations, but they are different from the conventions of mathematical logic. Imagine that a friend states "If I were Ann, I wouldn't do what she did" and we disagree. We might well say, "No, if you were Ann, you would do exactly what she did." Similarly, if we dispute the statement, "If Tom works overtime, then he's paid extra," we might say, "No, if Tom works overtime, he's not paid extra." Or to counter the claim that "If carbon emissions continue to occur at the present rate, the earth's temperature will increase by 10 degrees," we might say "No, even if carbon emissions continue to occur at the present rate, there does not necessarily have to be a 10-degree increase in the earth's temperature."

Another set of examples of differences between formal and informal discourse concerns quantified statements. In mathematics the distinction between "all" and "some" is crucially important. Whether a statement begins "for all" or "there exists" completely determines how to tell whether or not it is true and what we can deduce from it. Yet in ordinary language the statement "All $A$ are $B$ " is normally understood to imply 
the existence of at least one $A$, whereas in mathematical discourse we allow the statement to be vacuously true. In an informal setting if a person has certain knowledge that "All $A$ are $B$ " and only states that "Some $A$ are $B$," many people would regard the person as dishonest. In other words, the statement "Some $A$ are $B$ " is normally taken to imply that "Some $A$ are not $B$." But in mathematics, this implication is invalid. Similarly, in mathematical writing "Some $A$ is a $B$ " and "Some $A$ are $B$ " are both acceptable ways to express "There exists $x$ such that $x$ is an $A$ and $x$ is a $B$," but in informal discourse the two sentences are not logically equivalent. See Rips [37, pp. 22, 56, 228-9, 403-4] for a discussion of these phenomena.

Negations of quantified statements in mathematics cause students at least as much difficulty as negations of if-then statements. In ordinary English, one can negate a universal or existential statement in several different ways, one of which is simply to insert the word "not." For instance, to negate the statement "All grass is green," we may say "Some grass is not green," "Not all grass is green," or "All grass is not green." Some grammarians ask us to avoid the phrasing "All grass is not green" because it is potentially ambiguous (indicating either a denial of the given statement or an allegation about the nongreenness of every blade of grass), but the usage is widespread even in formal writing in high-level publications (such as "All juvenile offenders are not alike," Anthony Lewis, The New York Times, 19 May 1997, Op-Ed page) or in literary works (such as "All that glisters is not gold," "William Shakespeare, The Merchant of Venice, Act 2, Scene 7, 1596-1597).

Dubinsky and Yiparaki [10] show (and my own experiments confirm) that a significant fraction of students interpret "There is a positive number $b$ such that for all positive numbers $a, b<a$ " to mean the same as "For all positive numbers $a$, there is a positive number $b$ such that $b<a$ " when, in fact, these statements have opposite truth values. In formal logic, statements of the form "There exists an $x$ such that for all $y, P(x, y)$ " are interpreted according to a strict rule: the universal quantifier is encompassed within the scope of the existential quantifier. In informal speech, however, sentences in which an existential quantifier appears to the left of a universal quantifier are frequently interpreted in the opposite way, as if their logical form were for all ... there exists. Consider, for instance, the biblical proverb: "There is a time to every purpose under the heaven." The continuation in Ecclesiastes makes perfectly clear that the for all ... there exists meaning is intended. This way of interpreting such multiply quantified statements is so pervasive that it is difficult to think of an example of an ordinary sentence of the form "There is a ... for every ..." that a majority of people would express formally as there exists... for all. The data of Dubinsky and Yiparaki support this observation, as do linguists such as Chierchia and McConnellGinet [7].

Informal ways of expressing negations of statements containing and and or may also mislead students when they come to work in a formal mathematical setting. For instance, a person who expresses the negation of "John is tall and thin" as "John is not tall and thin," which is entirely correct, not only uses the word "and" but also avoids having to think about the specific circumstances that would falsify the given statement. So perhaps it should not be surprising that when students are asked to write the negation of "John is tall and John is thin," a large number respond with "John is not tall and John is not thin." Similarly, many students negate " $1 \leq x \leq 3$ " by writing " $1>x>3$."

Many examples of the special linguistic conventions used in formal mathematics can be found in Wells's Handbook of Mathematical Discourse [54].

\footnotetext{
${ }^{2}$ This quotation is often thought to be "All that glitters is not gold."
} 
4. INFLUENCE OF PREVIOUS INSTRUCTION IN MATHEMATICS. An additional reason for students' problems with formal mathematical reasoning in intermediate and upper-level college and university courses may result from their previous instruction in mathematics itself. Mathematics teachers often face a difficult dilemma: emphasize general principles or focus on concrete strategies. Emphasizing general principles probably leads to deeper understanding, but if time is limited, weaker students may fail to connect the principles with specific problems and therefore do relatively poorly on examinations. Focusing on narrow problem-solving strategies may lead to greater success for a larger fraction of students in solving standard problems, but it may obscure basic ideas and provide an inadequate basis for more advanced work. Given the pressures that have been mounting on teachers over the past several decades to help the majority of their students achieve success on standardized tests, it would be natural for some to choose strategies and short-cuts over general principles.

For example, calculus students who are encouraged to memorize what the chain rule looks like in each of the common cases $(u(x))^{n}, \cos (u(x)), \mathrm{e}^{u(x)}$, and so forth, often forget the general statement, but they may attain more rapid success with routine applications than students who are only shown the general formula and examples of how to apply it in each specific instance. Yet students who are taught always to work from the general formula are more likely to learn it well, and the resulting familiarity creates fertile ground for actual understanding to grow. Moreover, while the process of learning to apply the general formula to a large variety of instances may take more time than learning to apply more specialized formulas, students who achieve success develop greater understanding for the power of general mathematical theorems. They also deepen their intuition for the logical principle known as universal instantiation, thereby improving their ability to operate with abstract mathematical symbols.

Similar distinctions can be made between students who learn only the FOIL method for multiplying two binomials and those who learn a general strategy for multiplying one polynomial by another, between students who learn to use the vertical line test for whether a graph represents a function and those who learn to tell the difference between functions and nonfunctions by direct application of the definition of function, and between students who use a mechanical method for finding the inverse of a function and those who find the inverse by explicit use of the definition. For a more extensive discussion of these distinctions, see Epp [14], [15].

Presumably in an attempt to appear accessible, mathematicians frequently write definitions as if-then when they really intend them to be understood as if-and-only-if. Those who know that the only-if direction is supposed to be obvious have no difficulty making use of it when they reason about mathematical objects, but students often need to be taught how to use the only-if direction in mathematical situations.

Formal mathematical discourse itself may suggest flexibility about the interpretation of order of quantifiers because the telltale signal that a statement is universal sometimes appears as a trailer at the end of a statement rather than at its beginning, as, for example, when the commutative law is stated as " $a+b=b+a$ for all real numbers $a$ and $b$. .' Indeed, universal quantifiers are routinely suppressed entirely in formal mathematical writing, as when a function $f$ is defined to be even "iff $f(x)=f(-x)$," or when a relation $R$ is called symmetric "iff $a R b$ whenever $b R a$." Hazzan and Leron [24] point out some of the serious misunderstandings to which such suppression of quantifiers occasionally leads.

Ways in which mathematics instruction may subtly encourage students to confound conditional statements and their converses occur in the kinds of justifications given for mathematical theorems. For instance, a teacher's explanation may encourage students to remember the theorem asserting that if the first derivative of a function is posi- 
tive, then the function is increasing, by imagining a nice-looking increasing function whose derivative is everywhere positive, thereby indirectly leading them to conclude that the derivative of an increasing function is always positive. They may propose a similar mental image to help remember the relation between the second derivative and concavity. Of course, calculus also offers opportunities for pointing out the logical distinction between a conditional statement and its converse-in the relation between differentiability and continuity and the relation between convergence of a series and having the terms of the series tend to zero- - but these topics are discussed somewhat less often than in the past because of a trend to deemphasize "pathology" in elementary calculus and to move infinite series to a higher-level course.

Both Harel and Sowder [23] and Goetting [21, p. 1] refer to teachers' practice of omitting proofs of theorems and relying on examples as justification. In so doing, teachers may unwittingly convey the impression that empirical evidence suffices to establish the truth of mathematical statements. Hoyles [25] points out that some of the new curricula, which were designed to remedy past problems in mathematics education, may in fact be increasing students' belief in the sufficiency of empirical justification to establish general results. A number of recent textbooks contribute to this misperception. And although there is a worldwide move to require mathematics students at all levels to give explanations for their answers, at present this requirement is only imposed by a relatively small fraction of teachers. Many students arrive in a course emphasizing proof never having had to write a complete sentence in a mathematics course.

Senk [43] found that only 30 percent of a sample of students who took a one-year high school geometry course emphasizing traditional two-column proofs achieved a 75 percent mastery level. Her results were widely interpreted to indicate a failure of traditional methods and a need to focus more on developing intuition and understanding of basic geometric relationships through exploration of examples. Certainly, one deplores the idea of students going mechanically through abstract proof processes without a good intuition for fundamental aspects of geometry. But it is possible that the resulting de-emphasis on formal proof will lead to even fewer numbers of students emerging from secondary school with a real sense for deductive argument. If adequate measures are not taken to cultivate students' proof abilities as well as their familiarity with geometric objects, Senk's statistics may eventually come to be seen as signs of success rather than failure of traditional teaching methods.

\section{CAN INSTRUCTION HELP STUDENTS DEVELOP FORMAL REASON-}

ING SKILLS? The question of whether or not abstract reasoning skills developed in one domain can transfer to other domains has long been a subject of debate among psychologists and educators. For a historical summary, see Nisbett [34, pp. 1-9]. In one of the studies using the Wason selection task (a test of understanding of the logic of conditional statements) Cheng et al. [6] found no difference in performance between university students who had taken an introductory logic course and a control group of students who had not. An earlier study by Deer [8] also seemed to indicate that an explicit unit on logic was ineffective in improving high school students' ability to prove geometry theorems.

Although these studies provide evidence that traditional study of formal logic may not be sufficient to produce noticeable gains in students' reasoning abilities, the work of Cheng et al. [6] indicates that (1) when training in the abstract rules of logic is combined with training using concrete, discursive examples, improvement in students' reasoning performance is significantly greater than when either abstract training or examples training is administered alone, and (2) explaining logical principles by ref- 
erence to analogous "pragmatic reasoning schemas," such as are used in everyday discourse about permission and obligation, increases the likelihood that students will apply the principles in more abstract contexts. Similarly, a study by Platt [36] indicated that a unit in formal logic was beneficial for higher achieving geometry students and one by Mueller [32] suggested that instruction in logic could, in fact, lead to greater success in geometry if the logic units were interwoven with the geometry and if cues were given to help students realize the relevance of the logic to the specific geometry tasks. Berriozábal [4] also reports considerable long-term impact of the study of logic on the students in his TexPrep program.

Anderson, Reder, and Simon claim that the overall body of research about transfer of skills in cognitive psychology shows that "the amount of transfer depends on where attention is directed during learning." Regarding the effectiveness of training in the component skills that are needed to accomplish more complex tasks, they maintain that "the evidence shows that ... a learner who is having difficulty with components can easily be overwhelmed by the processing demands of the complex task" [2, p. 241] and that "a large history of research in psychology shows that part training is often more effective when the part component is independent, or nearly so, of the larger task" [2, p. 241]. But they also state that to achieve transfer of skills from one setting to another, "training on the cues that signal the relevance of an available skill may deserve much more emphasis than they now typically receive in instruction" [2, Internet version, paragraph 33].

Trying to change thinking habits, especially ones that have become ingrained over a period of years, is a very difficult task. Many cognitive psychologists believe that the human brain consists of multiple parts that operate more or less independently and often do not communicate very well with each other. For a general discussion of this model of brain function see, for example, Gazzaniga [19] or Minsky [29], and for a discussion of some of its implications for the process of learning mathematics see Tall [47]. The novelist George Eliot expressed insight into this phenomenon more than a hundred years ago when she wrote: "The human soul is hospitable, and will entertain conflicting sentiments and contradictory opinions with much impartiality" [11, Proem]. A likely consequence for mathematics instruction is that in order to learn a complex process such as proof and disproof, effective integration of new modes of thought with pre-existing contradictory modes is a major undertaking. It is not surprising that easy solutions have not yet been discovered.

Despite their difficulties, students are often grateful for the opportunity to understand the underlying structure of mathematical thought on a deeper level than they had previously been exposed to. Instructors who evaluate their work may wish that they had made greater progress, but the students often believe they have achieved a great deal. A recent questionnaire, which asked students about the general mathematics program at DePaul University, contained a question inquiring what course had been most beneficial and in what way. A significant fraction of the students in a postcalculus "Introduction to Mathematical Reasoning" class cited that class as most beneficial, giving as their reason that it had helped them improve their logical reasoning skills.

\section{AT WHAT POINT SHOULD THE PRINCIPLES OF LOGIC BE INTRO-}

DUCED? In the 1930s the Russian psychologist L. S. Vygotsky coined the phrase "zone of proximal development" [52, pp. 84-91, 102]. I believe that these words articulate a profound truth about education, namely, that at any given point in the learning process, the insight and intuitions the learner has previously developed provide a basis that determines the amount that can be accomplished in the next stage of instruction. In the afterword of their edited collection of Vygotsky's work, Mind and Society, editors 
V. John-Steiner and E. Souberman summarized his thinking as follows: "To implement the zone of proximal development in instruction, psychologists and educators must collaborate in the analysis of the internal ('subterranean') developmental processes which are stimulated by teaching and which are needed for subsequent learning" [52, p. 131].

The first few times I taught a course with a focus on developing mathematical reasoning, I covered preliminary material on logic in the briefest and most perfunctory way before launching into specific topics such as sets, functions, and relations. In time, however, I came to see benefit in helping students broaden their zone of proximal development before introducing them to the concepts of proof and disproof proper. As a result, I now spend a few weeks at the beginning of the course discussing basic notions of elementary logic and giving students formal and informal practice in working with the language of the logical connectives and the quantifiers.

Some mathematics educators are impatient with this approach. They argue that logic is too dry to capture students' interest and that it is more important to engage students right away with interesting mathematical problems that will lead them to see the need for proof and disproof. A drawback to this method, however, is that some members of the class may lack sufficient logical apparatus to acquire the understandings the instructor thinks must inevitably follow from considering the mathematical problems. In some cases, problems may be adequately solved in group settings by more able members of the class while the rest of the students flounder and lack the intellectual scaffolding to help them catch up. Meanwhile, even strong students may make mistakes because of a lack of knowledge of logical principles and fail to achieve insights about the problem-solving process that a background in logic would have enabled them to recognize.

If instructors could spend extended periods in one-on-one discussions with students, they could focus as needed on just those issues that were causing difficulty. However, as Harel and Sowder note, "While this approach [individual discussions] appeared to be effective, it demanded from the instructors, as was expected, enormous amounts of time outside the regular classroom hours" [23, p. 279]. Since instructors' time is limited, it may simply be more efficient to incorporate an introductory unit on the principles of logical reasoning and the associated linguistic conventions in a course where a primary theme is proof and disproof. This approach does not, of course, eliminate all difficulties, but it does cut down on the amount of time and effort needed to resolve them.

Another important reason for discussing logic explicitly is to help prepare the next generation of teachers. Unfortunately, at least in the United States, a large number of $\mathrm{K}-12$ teachers have only a weak command of the principles of logical reasoning. It is simply not possible for such teachers to promote effectively their students' reasoning development (as is expected by the NCTM Principles and Standards of School Mathematics [33]) when they themselves do not have a feeling for what is or is not a valid deduction or what it means for statements of various forms to be true or false.

The extent to which we eliminate proof in the broad sense from the $\mathrm{K}-12$ curriculum and the first two years of college is the extent to which we perpetuate the weakness of our teachers. For one thing, when careful deductive reasoning is virtually absent from lower-level mathematics courses, the wrong people may be attracted to the subject. Too often, such students do adequate work through the first two years of college and then barely squeak through the remaining courses in their degree programs. Interviews by Bonn and Olson [5] and by Pagallo and Blue [35] with students majoring in secondary mathematics education indicate that some actually disdain higher-level, more rigorous mathematics courses because they believe (from their own experience!) 
that they will not need to understand this material or these modes of thought in their future teaching.

7. TEACHING LOGICAL REASONING. Unfortunately, as noted earlier, it is possible to teach logic in a mechanical way that does not appear to have much effect on most students' reasoning abilities. I believe in presenting logic in a manner that continually links it to language and to both real-world and mathematical subject matter, following up by referring to logical principles as they arise later in the course. Starting with logic makes the course seem coherent and provides students with a supportive framework, which they can lean on while the various aspects of proof and counterexample are falling into place. It builds students' confidence in the rationality of the mathematical enterprise and helps allay their fear of failure. Determining truth and falsity of mathematical statements is so complex that, even when they are motivated, students often fail to "get it" if they do not have some knowledge and experience with basic logical tools. Preceding the discussion of proof and disproof with a treatment of logic provides a language for instructors to explain why mathematicians do the things they do when they prove and disprove mathematical statements and to communicate with their students when they make mistakes.

Exploiting similarities between formal and everyday language. Although there are many differences between everyday and mathematical language, almost all the linguistic conventions of mathematics can be found somewhere in ordinary discourse. For instance, most students understand that "If Sam lives in Chicago, then Sam lives in the U.S." does not imply that "If Sam lives in the U.S., then Sam lives in Chicago." They also easily see that to disprove "All the people in this room are at least twenty years old," it suffices to find a single person in the room under the age of twenty.

Some students are not quite so quick to understand that "Italy will win the World Cup only if it wins tonight's game" is equivalent to "If Italy does not win tonight's game, then it will not win the World Cup," and that these statements do not imply that "If Italy wins tonight's game, then it will win the World Cup." But almost all come to develop an intuitive feel for these relationships if given an opportunity to think them through, as in a class discussion.

To motivate students to accept the reasonableness of the principles of mathematical reasoning, it is helpful to introduce each principle with examples of sentences whose "natural" interpretation agrees with the one used in standard logic. One can even suggest that students learn a few of these sentences to refer to as prototypes when they are unsure about how to interpret formal mathematical statements. It is also helpful, however, to acknowledge explicitly some of the differences between mathematical logic and the logic used in everyday life. This aids students in resolving what otherwise would be contradictory and assists them in integrating the new rules into a cognitive framework. Moreover, by pointing out that the logic used in mathematics is essentially just a small fraction of the much more complex logic they are accustomed to using, they are encouraged to conclude that mathematical logic will not be so difficult to learn.

Translation exercises. Symbolic summaries of logical principles are concise and help focus students' attention on essentials. Nonetheless, as indicated earlier, there is evidence that simply memorizing abstract logical formulas and learning to apply them mechanically has little impact on students' broader reasoning powers. Thus, in the sections on logic, one can emphasize exercises where students apply logical principles to a mix of carefully chosen natural language and mathematical statements. It is es- 
pecially useful to stress the formulation of negations, because to be able to evaluate whether or not a statement is true, one must understand what it would mean for it to be false.

Furthermore, because of the importance of quantified statements in mathematics and because of the large variety of different ways such statements are expressed informally in mathematical writing, it is desirable to give students quite a bit of practice translating back and forth between formal and informal modes of expression. Seldin and Seldin cite students' weak ability to "unpack informally written mathematical statements into the language of predicate calculus" [41, p. 123] as a significant stumbling block to their ability to construct and validate proofs. One way to work up to translation exercises involving quantified statements is to begin modestly by having students evaluate statements for small finite systems such as those in Tarski's World used by Barwise and Etchemendy [3]. Then one can ask students to write statements such as the following informally in several different ways without using variables or formal quantifiers: " $\forall$ integers $n$, if $n^{2}$ is even then $n$ is even." Or one can ask them to rewrite a statement like "Every polynomial function is continuous" in the form: " $\forall \ldots$, if __ then __. In [30] Moore reported that students in a transitionto-higher-mathematics course made good progress in learning to perform such translations and that a number cited the experience as contributing to their ability to do proofs.

Some students pick up the finer points of English usage without explicit instruction-the difference between "affect" and "effect" or between "lie" and "lay," for example - but most need a teacher's help to become aware of these distinctions and learn to make them reliably. Similarly, a large majority of students need assistance to become linguistically adept in a mathematical environment. Many students lack respect for symbols and the "little" words-symbols like = and words like if, and, and or-that make such a difference to the interpretation of mathematical statements. Exercises that mix logic, language, and mathematics help sensitize them to the importance of such expressions. Because of the complexity and subtlety of the logic of ordinary discourse, however, it is important to formulate such translation exercises carefully, so as to make them unambiguous and meaningful.

Use of truth tables. What role should truth tables play in communicating the principles of logical reasoning? I believe it is important for students to learn to express the definitions of not, and, or, and if-then in words, not just to see the definitions in a table. For instance, they should understand that an and statement is true if, and only if, both components are true, and that an if-then statement is false if, and only if, its hypothesis is true and its conclusion is false. Facts about negations of forms of statements follow naturally from such formulations.

Using truth tables to a limited extent, however, does help some students organize their knowledge about logical principles and gives them concrete objects to hang onto while they deal with the abstraction of the logic. It is important to make clear, though, that truth tables merely summarize all the various possible truth values that may be taken by a compound statement of a given form-values that are completely determined by the truth values of the component statements.

And although truth tables can help convey the concepts of logical equivalence and validity and invalidity of arguments, one must take pains to steer students away from interpreting them mechanically. For instance, students will often say that a truth table shows the logical equivalence of two statement forms "because the results match," and it can be very difficult to get them to make the connection that the "results" are truth values. When this problem arises in my classes and once the connection has been 
made clear through class discussion, I strongly urge students to explain their finding of logical equivalence by writing something like "because the table shows that the two forms of statement always have the same truth values." Absent an explanation, the process of constructing and interpreting the truth table may do little to advance their understanding of the concept of logical equivalence.

In a similar way students can learn a procedure to test for validity of an argument form without understanding the concept of validity, simply by mechanically converting the argument to a tautology and checking that all the truth values are $T$. So I require students to identify the columns containing the premises and the conclusion and check that in every case where the premises are true the conclusion is also true. I also insist that they include an explanation with their answer, and the explanations in the model answers I give them are written so as to emphasize concepts. For example, to explain how a table shows invalidity, I suggest that they annotate the table by pointing an arrow to the appropriate row(s) and urge them to write something like "This row shows that it is possible for an argument of this form to have true premises and a false conclusion. Hence this form of argument is invalid."

Dealing with transfer issues. As a course with an emphasis on proof progresses, one can follow the advice about transfer issues given by Anderson, Reder, and Simon to help students recognize "the cues that signal the relevance of an available skill" [2, Internet version, paragraph 33] by continuing to refer explicitly to logical principles as they arise naturally in mathematical contexts. Thus, for example, in introducing the notions of formal proof and counterexample, one can refer back to the definition of truth and falsity of a universal statement and recall a simple example, such as how to disprove that every person in the room is at least twenty years old. One would naturally follow up with mathematical examples that make the same point, but it is helpful to ground the discussion in something very basic that has been previously considered.

Similarly, when one talks about the reasons for steps in proofs, one can point out how in most cases they are applications of the principle of universal instantiationknowing that if a property holds for all elements in a set, then it holds for any particular element in the set. And when students have difficulty finding counterexamples or starting off proofs by contradiction, their frustration is reduced when they realize that they have only to make use of a skill they learned fairly well before, namely, how to formulate the negation of a statement.

It takes time for students to come to accept the validity of logical principles in all their generality. For example, prior to a discussion of one-to-one functions not all students may have achieved an intuitive feeling for the logical equivalence between a conditional statement and its contrapositive. But both their understanding of oneto-one functions and their understanding of logic is enhanced when they perform the exercise of stating the contrapositive of the standard form of the definition of one-toone and contemplate the equivalence in that particular situation. Indeed, since students would have studied proof by contradiction by such a point in the course, an instructor could offer a proof by contradiction that, if a conditional statement is true, then so is its contrapositive. Some students find such a proof more convincing than a proof that uses truth tables.

Another example occurs when one discusses properties of binary relations. Learning to evaluate whether they possess various properties is much easier for students who are familiar with how to take the negation of universal conditional statements. Moreover, pointing out that the definitions of the properties are both universal and conditional and reviewing the implications of these facts helps the weaker students whose command of the subject is still shaky. And stronger students are often charmed 
to encounter examples of binary relations that are symmetric or transitive because the definition of the property is vacuously true.

\section{REFERENCES}

1. J. R. Anderson, Cognitive Psychology and Its Implications, 3rd ed., Freeman, New York, 1990.

2. J. R. Anderson, J. R., L. M. Reder, and H. A. Simon, Radical constructivism and cognitive psychology, in Brookings Papers on Education Policy, D. Ravitch, ed., Brookings Institution, Washington, D.C., 1998, pp. 227-255. (A more complete version, "Applications and Misapplications of Cognitive Psychology to Mathematics Education," is available on the Internet at http://act.psy.cmu.edu/ACT/papers/misappliedabs-ja.html.)

3. J. Barwise and J. Etchemendy, The Language of First Order Logic, 3rd ed., University of Chicago Press, Chicago, 1992.

4. M. Berriozábal, The Texas prefreshman engineering program: Filling the pipeline for workforce diversity, Proceedings of the National Symposium and Career Fair of the Society of Mexican-American Engineers and Scientists, 1995.

5. K. Bonn and D. Olson, Oral presentation at the Conference on Research in Undergraduate Mathematics Education, South Bend, IN, September 1998.

6. P. W. Cheng, K. J. Holyoak, R. E. Nisbett, and L. M. Oliver, Pragmatic vs. syntactic approaches to training deductive reasoning, Cognitive Psychology 18 (1986) 293-328.

7. G. Chierchia and S. McConnell-Ginet, Meaning and Grammar: An Introduction to Semantics, MIT Press, Cambridge, 1990.

8. G. W. Deer, The Effects of Teaching an Explicit Unit in Logic on Students' Ability to Prove Theorems in Geometry, doctoral dissertation, Florida State University, 1969.

9. E. Dubinsky and W. E. Fenton (contributor), Introduction to Discrete Mathematics with Isetl, SpringerVerlag, New York, 1996.

10. E. Dubinsky and O. Yiparaki, On student understanding of AE and EA quantification, in Research Issues in Collegiate Mathematics Education IV, E. Dubinsky, A. H. Schoenfeld, and J. Kaput, eds., CBMS Issues in Mathematics Education, vol. 8, American Mathematical Society, Washington, D.C., 2000, pp. 239-289.

11. G. Eliot, Proem to Romola, 1862-63; reprinted by Penguin Putnam, New York, 1997.

12. S. S. Epp, The logic of teaching calculus, in Toward a Lean and Lively Calculus, R. G. Douglas, ed., Mathematical Association of America, Washington, D.C., 1987, pp. 41-60.

13. - Discrete Mathematics with Applications, 2nd ed., Brooks/Cole, Belmont, CA, 1995.

14. Logic and discrete mathematics in the schools, in Discrete Mathematics in the Schools, D. Franzblau and J. Rosenstein, eds., American Mathematical Society, Providence, 1997, pp. 75-84.

15. - The language of quantification in mathematics instruction, in Developing Mathematical Reasoning in Grades K-12, F. R. Curcio and L. V. Stiff, eds., National Council of Teachers of Mathematics, 1999, pp. $188-197$.

16. J. St. B. T. Evans, The Psychology of Deductive Reasoning, Routledge \& Kegan Paul, London, 1982.

17. E. Fishbein and I. Kedem, Proof and certitude in the development of mathematical thinking, in Proceedings of the 6th Conference of the Psychology of Mathematics Education, A. Vermandel, ed., Antwerp, 1982, pp. 128-131.

18. P. Fletcher, and C. W. Patty, Foundations of Higher Mathematics, 3rd ed., Brooks/Cole, Belmont, CA, 1995.

19. M. S. Gazzaniga, The Social Brain: Discovering the Networks of the Mind, Basic Books, New York, 1985.

20. J. L. Gersting, Mathematical Structures for Computer Science, 5th ed., W. H. Freeman, New York, 2002.

21. M. M. Goetting, The College Student's Understanding of Mathematical Proof, doctoral dissertation, University of Maryland, 1995.

22. D. Gries and F. B. Schneider, A Logical Approach to Discrete Math, Springer-Verlag, New York, 1993.

23. G. Harel and L. Sowder, Students' proof schemes: Results from exploratory studies, in Research in Collegiate Mathematics Education III, A. H. Schoenfeld, J. Kaput, and E. Dubinsky, eds., American Mathematical Society, Providence, 1998, pp. 234-283.

24. O. Hazzan and U. Leron, Students' use and misuse of mathematical theorems: The case of Lagrange's theorem, For the Learning of Mathematics 16 (1996) 23-26.

25. C. Hoyles, The curricular shaping of students' approaches to proof, For the Learning of Mathematics $\mathbf{1 7}$ (1997) 7-16.

26. R. Johnsonbaugh, Discrete Mathematics, 5th ed., Prentice Hall, Upper Saddle River, NJ, 2001.

27. J. F. Lucas, Introduction to Abstract Mathematics, 2nd ed., Ardsley House, New York, 1990. 
28. J. Mason (with L. Burton and K. Stacey), Thinking Mathematically, Addison-Wesley, Reading, MA, 1982.

29. M. Minsky, The Society of Mind, Heinemann, London, 1987.

30. R. C. Moore, College Students' Difficulties in Learning to Do Mathematical Proofs, doctoral dissertation, University of Georgia, 1990.

31. Making the transition to formal proof, Educ. Stud. Math. 27 (1994) 249-266.

32. D. J. Mueller, Logic and the Ability to Prove Theorems in Geometry, doctoral dissertation, Florida State University, 1975.

33. National Council of Teachers of Mathematics, Principles and Standards for School Mathematics, 2000.

34. R. E. Nisbett, Reasoning, abstraction, and the prejudices of 20th century psychology, in Rules for Reasoning, R. E. Nisbett, ed., Lawrence Erlbaum Associates, Hillsdale, NJ, 1993.

35. J. A. Pagallo and W. A. Blue, Analyzing the value of a transitional mathematics course, in Assessment Practices in Undergraduate Mathematics, B. Gold, S. A. Keith, and W. A. Marion, eds., Mathematical Association of America, Washington, D.C., 1999, p. 66.

36. J. L. Platt, The Effect of the Use of Mathematical Logic in High School Geometry: An Experimental Study, doctoral dissertation, Colorado State College, 1967.

37. L. J. Rips, The Psychology of Proof: Deductive Reasoning in Human Thinking, MIT Press, Cambridge, 1994.

38. K. Rosen, Discrete Mathematics and its Applications, 5th ed., McGraw-Hill, New York, 2002.

39. K. A. Ross and C. R. B. Wright, Discrete Mathematics, 5th ed., Prentice Hall, Upper Saddle River, NJ, 2002.

40. A. H. Schoenfeld, Mathematical Problem Solving, Academic Press, New York, 1985.

41. A. Selden and J. Selden, Unpacking the logic of mathematical statements, Educ. Stud. Math. 29 (1995) 123-151.

42. - The Role of Logic in the Validation of Mathematical Proofs, Tennessee Technological University Mathematics Department Technical Report No. 1999-1, 1999; also available at www.cs.cornell.edu/Info/ People/gries/symposium/symp.htm.

43. S. L. Senk, How well do students write geometry proofs?, Mathematics Teacher 78 (1985) 448-456.

44. D. Smith, M. Eggen, and R. St. Andre, A Transition to Advanced Mathematics, 5th ed., Brooks/Cole, Belmont, CA, 2001.

45. D. Solow, How to Read and Do Proofs: An Introduction to Mathematical Thought Processes, 3rd ed., Wiley, New York, 2001.

46. D. O. Tall, ed., Advanced Mathematical Thinking, Kluwer Academic Publishers, Dordrecht, The Netherlands, 1991.

47. - The psychology of advanced mathematical thinking, in [46], pp. 3-21.

48. D. O. Tall and S. Vinner, Concept image and concept definition in mathematics with particular reference to limits and continuity, Educ. Stud. Math. 12 (1981) 151-169.

49. D. R. Thompson, Learning and teaching indirect proof, Mathematics Teacher 89 (1996) 474-482.

50. D. J. Velleman, How to Prove It: A Structured Approach, Cambridge University Press, Cambridge, 1994.

51. S. Vinner, The notion of proof-some aspects of students' views at the senior high level, in Proceedings of the 7th Conference of the Psychology of Mathematics Education, R. Hershkowitz, ed., Shoresh, Israel, 1983, pp. 289-94.

52. L. S. Vygotsky, Mental development of children and the process of learning, in Mental Development of Children during Education, Uchpedgiz, Moscow, 1935, pp. 20-32 (Russian); translated as part of Mind in Society, M. Cole et al., eds., Harvard University Press, Cambridge, 1978.

53. P. C. Wason, Reasoning, in New Horizons in Psychology I, B. M. Foss, ed., Penguin, Harmondsworth, UK, 1966.

54. C. Wells, The Handbook of Mathematical Discourse, Version 0.9 (2002); available at http:// www.cwru.edu/artsci/math/wells/pub/abouthbk.htm; print version, Infinity Publishing, Haverford, PA (to appear).

SUSANNA S. EPP received her Ph.D. in 1968 from the University of Chicago, taught briefly at Boston University and the University of Illinois at Chicago, and is currently professor of mathematical sciences at DePaul University. After initial research in commutative algebra, she became fascinated by the cognitive issues associated with teaching analytical thinking and proof and has made their exploration the primary focus of her professional work. She was coauthor of Precalculus and Discrete Mathematics, which was developed as part of the University of Chicago School Mathematics Project, and is now preparing her widely used book Discrete Mathematics with Applications for a third edition. Long active in the Mathematical Association of America, she is a member of the writing group developing the new set of curricular guidelines, Undergraduate Programs and Courses in the Mathematical Sciences: CUPM Curriculum Guide 2004.

Department of Mathematical Sciences, DePaul University, Chicago, IL 60614, sepp@ condor.depaul.edu 